\title{
A relevância da pesquisa para o Serviço Social: conquistas e desafios permanentes das Diretrizes Curriculares
}

\author{
Rayane Noronha Oliveira \\ Tássia Monte Santos \\ https://orcid.org/0000-0002-1987-7959 \\ https://orcid.org/0000-0003-2096-7975 \\ ${ }^{1}$ Universidade Federal do Rio Grande do Norte, Departamento de Serviço Social, Programa de Pós-Graduação em Serviço Social, Natal, \\ RN, Brasil \\ ${ }^{2}$ Universidade Federal do Rio Grande do Norte, Departamento de Serviço Social, Curso de Serviço Social, Natal, RN, Brasil
}

\begin{abstract}
A relevância da pesquisa para o Serviço Social: conquistas e desafios permanentes das Diretrizes Curriculares

Resumo: Este artigo objetiva elencar alguns subsídios para o diálogo da pesquisa na formação do/a assistente social, no âmbito acadêmico, a partir do que preconizam as Diretrizes Gerais para o Curso de Serviço Social (1996). Para tanto, realizamos uma pesquisa bibliográfica e documental, de cunho qualitativo, analisando as legislações que regulam a profissão em relação à pesquisa e demais produções científicas pertinentes, sob a perspectiva do materialismo histórico-dialético. Concluímos que, diante dos atuais desafios relacionados à expansão das correntes contra-hegemônicas no serviço social e da expansão do Ensino a Distância, a profissão precisa voltar a colocar-se na agenda das suas próprias pesquisas, isto é, ser objeto das investigações realizadas pela comunidade de pesquisadores da área. Uma nova pesquisa sobre a implementação das Diretrizes Curriculares, por exemplo, poderia abrir possibilidades de um novo debate nacional.
\end{abstract}

Palavras-chave: Pesquisa. Diretrizes Curriculares. Serviço Social.

\section{The relevance of research for Social Work: Permanent achievements and challenges of Curriculum Guidelines}

Abstract: This article offers subsidies to support the dialogue regarding research about the social workers' academic education, based on the document Diretrizes Gerais para o Curso de Serviço Social (1996) (General Guidelines for Social Work Programs). A qualitative bibliographic and documentary research was conducted to analyze the laws that regulate the profession regarding research and other relevant scientific productions, from the perspective of historical-dialectical materialism. The results show that, given the current challenges related to the expansion of counter-hegemonic currents in social work and the expansion of Distance Education, the profession needs to resume the agenda of researching the profession of social work itself. Thus, the analysis encourages the community of researchers in the field to consider social work as an object of study. Finally, the article suggests the development of new research on the implementation of the curriculum guidelines, for example, as a way to instigate a national debate on the subject.

Keywords: Research. Curriculum Guidelines. Social Work.

Recebido em 30.06.2019. Aprovado em 17.09.2019. Revisado em 12.11.2019.

(C) O(s) Autor(es). 2020 Acesso Aberto Esta obra está licenciada sob os termos da Licença Creative Commons Atribuição-NãoComercial 4.0 Internacional (https://creativecommons.org/licenses/by-nc/4.0/deed.pt_BR), que permite copiar, distribuir e reproduzir em qualquer meio, bem como adaptar, transformar e criar a partir deste material, desde que para fins não comerciais e que você forneça o devido crédito aos autores e a fonte, insira um link para a Licença Creative Commons e indique se mudanças foram feitas. 


\section{Introdução}

A pesquisa é a ferramenta que possibilita o desvendamento da realidade efetiva, isto é, da ordem de funcionamento da relação dos objetos reais existentes no mundo factual. A captação da concreticidade do mundo existente é uma tarefa que resulta de formas distintas da produção do conhecimento. A pesquisa de cunho científico é na vida e no mundo moderno, a forma pela qual o conhecimento se estrutura como referência e autoridade da verdade sobre a existência de infinitos objetos, desde a vida material orgânica aos complexos da subjetividade humana.

Portanto, a pesquisa é o mecanismo pelo qual desvendamos o existente, por meio do exercício treinado, interessado e destinado a constituir mediações capazes de garantir uma relação de apropriação e dominação inteligível sobre as legalidades naturais e sociais. Para a sua realização faz-se necessário uma metodologia e um método de análise, com rigor teórico-metodológico. A primeira se diz respeito as técnicas e instrumentos de manuseio da própria pesquisa. O segundo é a perspectiva que orienta a análise dos dados coletados, dos fenomênos sociais em questão.

A ciência se constituiu, historicamente, como uma mediação ontologicamente vinculada às problemáticas de ordem universal. Esse seu caráter de totalidade se desfigura através da ramifícação do conhecimento científico, que percorre a própria dinâmica da divisão sociotécnica do trabalho, na sociedade capitalista. Evidente, há grandes contradições nesses processos, em termos da produtividade e da qualidade do conhecimento que a sociedade construiu até aqui. É com base nesses fundamentos que podemos historicamente compreender a fragmentação das áreas de conhecimento tal como conhecemos hoje.

\section{É importante atentar para o}

fato de que o conhecimento

científico, como força

instrumental do

desenvolvimento da sociedade,

constitui-se objeto de disputa

de interesses. $O$ interesse

social das classes é radicado

nas determinações e relações

fundantes da vida social,

formatada pelas relações de

produção e reprodução social.

Na pluralidade das Ciências Sociais situam-se diferentes caminhos analíticos, como o Positivismo, a Sociologia Compreensiva e o Materialismo Histórico-Dialético (MHD), tendo como seus grandes expoentes, respectivamente, os teóricos Émile Durkheim (França, 1858-1917), Max Weber (Alemanha, 1864-1920) e Karl Marx (Alemanha, 1818-1883), que marcaram não apenas a emergência da Sociologia, mas também a produção teórica-clássica da teoria social moderna. Destes autores sucederam-se diversas linhas teóricas e perspectivas analíticas diferentes. Da sociologia compreensiva, por exemplo, derivou-se a fenomenologia. Da teoria marxista, a teoria crítica da Escola de Frankfurt.

O Serviço Social, ao longo de sua trajetória histórica, esteve orientado, em maior ou menor medida, por todas as três grandes perspectivas da Sociologia, a começar pelo positivismo, em sua gênese, passando pela fenomenologia, durante a reatualização do conservadorismo e aderindo ao materialismo histórico-dialético no período de intenção de ruptura até a atualidade (PAULO NETTO, 2017). Essas perspectivas fundamentaram a via analítica e, consequentemente, a intervenção profissional, marcando ainda hoje uma característica sincrética do exercício profissional, mediada pelos desafios postos pela fase superior capitalista em seu estágio monopolista, que faz com que a "questão social" assuma feições dramáticas e complexas (SOUZA, 2014).

Como em diversas outras áreas, no Serviço Social a pesquisa possui uma dimensão científica (teórica) e outra prática/interventiva, ultrapassando o dicotomismo e compondo uma unidade indissociável que está presente na formação e no exercício profissional, que contradiz a ideia de que na prática a teoria é outra (SANTOS, 2011). Tendo como norte a importância da pesquisa e as suas contribuiçốes para o Serviço Social, este artigo objetiva elencar alguns subsídios para o diálogo da pesquisa na formação do/a assistente social, no âmbito acadêmico, a partir do que preconizam as Diretrizes Gerais para o Curso de Serviço Social (1996).

Para tanto, realizamos uma pesquisa bibliográfica e documental, de cunho qualitativo, analisando as legislações que regulam o Serviço Social em relação à pesquisa e demais produções científicas pertinentes. Para a análise, adotamos o materialismo histórico-dialético, por ser uma ferramenta de análise da vida social, que ajuda ultrapassar a aparência dos acontecimentos e orienta a busca da dinâmica interna dos objetos da investigação, da captura da essência e das múltiplas determinações que incidem sobre os fenô- 
menos sociais, na perspectiva de desvendar a realidade e questionar criticamente a sua lógica social, como síntese de uma práxis transformadora.

Por fim, esse artigo encontra-se dividido em duas partes principais. A primeira se destina a situar o local da pesquisa no Serviço Social, traçando seus marcos sociais, políticos e legais, assim como os principais desafios para a efetivação das Diretrizes Curriculares, na atualidade. A segunda parte consiste no debate em torno do método materialista histórico-dialético e sua utilização enquanto ferramenta analítica nas pesquisas do Serviço Social, elencando alguns desafios que merecem ser melhor estudados e analisados, que encontram-se articulados aos avanços das contradições do capitalismo contemporâneo, do pensamento pós-moderno e do crescente aumento das instituições de Ensino a Distância (EaD).

\section{O lugar da pesquisa no serviço social: uma conquista em meio a ameaças}

A pesquisa compõe uma das faces da dimensão investigativa do exercício do/a assistente social (GUERRA, 2009) e constitui uma ferramenta imprescindível no processo de formação. Estudantes da graduação devem cursar, obrigatoriamente, disciplinas relacionadas à pesquisa. Essa é uma das conquistas datadas da aprovação do currículo mínimo em 1982, que alterou significamente o debate em torno da história, teoria e método, além das análises referentes às políticas sociais e aos movimentos sociais, dentro da profíssão, afirmando uma nova direção social hegemônica, acadêmica e profissional.

Nas Diretrizes Gerais para o Curso de Serviço Social, com base no currículo mínimo, aprovado em novembro de 1996, a pesquisa passa a ser uma das partes indispensáveis para a formação profissional, configurando-se para além de uma matéria, ao incorporar o tripé ensino-pesquisa-extensão. Essas conquistas são reflexos do processo de articulação política dentro do próprio movimento de reconceituação, que alterou a maneira que o Serviço Social compreendera as contradições da sociedade capitalista brasileira, filiando-se a uma perspectiva crítica-analítica fundamentada no materialismo histórico-dialético.

Em suma, numa ordem cronológica, podemos elencar vários fatores históricos dentro da profíssão que nos ajudam a compreender a incorporação da pesquisa e seu aperfeiçoamento na formação e no exercício profissional, a começar pelo próprio movimento de reconceituação, iniciado na década de 1960; a maturidade científica da profissão, com a proximidade à teoria marxista e marxiana; a criação dos cursos de pós-graduação, a partir da década de 1972; a aprovação do currículo mínimo, em 1982; e a legitimação e consolidação do Serviço Social como área de conhecimento pelo Conselho Nacional de Desenvolvimento Científico e Tecnológico (CNPq), em 1984; a aprovação do Código de Ética e o sancionamento da Lei de Regulamentação, em 1993, e a própria aprovação das Diretrizes Gerais, em 1996. Sendo que nessa longa trajetória histórica destacam-se a atuação da ABESS/ABEPSS ${ }^{1}$, além do conjunto CFESS/CRESS, da Executiva Nacional de Estudantes de Serviço Social (ENESSO) e de outros sujeitos políticos coletivos.

O processo de normatização das Diretrizes Gerais esteve em sintonia com a promulgação da Lei de Diretrizes Básicas da Educação - Lei n. 9.394, de 1996, estabelecendo um patamar comum, concomitantemente, da "flexibilidade, descentralização e pluralidade no ensino em Serviço Social, de modo a acompanhar transformações da ciência e da tecnologia na contemporaneidade" (ASSOCIAÇÃO BRASILEIRA DE ENSINO E PESQUISA EM SERVIÇO SOCIAL, 1996, p. 4). Essa demanda relaciona-se com as novas materialidades da questão social frente às contrarreformas do Estado, à crise e ao desemprego estruturais no capitalismo, as expressões do neoconservadorismo, à hegemonia dos paradigmas pós-modernos nas Ciências Sociais e à decadência da filosofia (COUTINHO, 1972). Essa realidade posta no nível do cotidiano dos/as inúmeros assistentes sociais, exige qualificação na apreensão da realidade, para sua posterior intervenção. Desse modo, investigação, pesquisa e intervenção são uma unidade indissociável do exercício profíssional do/a assistente social.

\footnotetext{
Mas é preciso dizer, também claramente, que todo/a assistente social, no seu campo de trabalho e intervenção, deve desenvolver uma atitude investigativa: o fato de não ser um/a pesquisador/a em tempo integral não o/a exime quer de acompanhar os avanços dos conhecimentos pertinentes ao seu campo de trabalho, quer de procurar conhecer concretamente a realidade da sua área particular de trabalho. Este é o principal modo para qualificar o seu exercício profissional, qualificação que, como se sabe, é uma prescrição do nosso próprio Código de Ética. (PAULO NETTO, 2009, p. 800).
}

Para tanto é necessário que a pesquisa esteja espraiada na formação profíssional, por meio do ensinopesquisa-extensão, para refletir no exercício profissional, alinhando-se com o que também estabelece o Código de Etica, que descreve o aprimoramento intelectual, na perspectiva da competência profissional e a liberdade de realizar pesquisas e estudos, além da participação de espaços que tenham por finalidade a 
produção de conhecimento científico (BARROCO; TERRA, 2014). Assim como a própria Lei de Regulamentação da Profíssão (Lei n. 8.662/1993)², para além da Lei de Diretrizes Curriculares (1996), que também destacam a importância da pesquisa na formação e no exercício profissional.

Podemos afirmar que pesquisa garante "o estatuto de maioridade intelectual para a profissão: além de possibilitar aos seus protagonistas uma contribuição efetiva às diversas áreas de conhecimento" (GUERRA, 2009 , p. 809). É por meio da pesquisa que os/as assistentes sociais se conectam às demandas da classe trabalhadora, efetivando também um retorno a essas demandas com a intervenção e a prática profisssional. Evidentemente, o/a assistente social aprende a produção da pesquisa durante a graduação, aperfeiçoando-a por meio da formação contínua que pode ocorrer concomitantemente à prática profissional.

Na graduação os/as alunos aprendem a maneira de compreender os fenômenos sociais, que implicará na maneira de intervir do futuro/a assistente social. Conhecer apenas como se expressa a realidade, mantendo o predomínio da aparência, sem investigar as suas causas, é compactuar com a reprodução e manutenção da realidade, dando enfoque a racionalidade formal-abstrata. Em contraposição a essa lógica, "o conhecimento oriundo da razão dialética capta o movimento do objeto, a sua lógica de constituição, percebe o que o objeto é e como chegou a ser o que é (seu processo de constituição), quais seus fundamentos, sua capacidade de transformar-se em outro". (GUERRA, 2009, p. 814). Portanto, a intervenção fundamentada no conhecimento oriundo da razão dialética possibilita transpor a imediaticidade da vida cotidiana, portando-se para além do fenomênico. Essa é uma das principais contribuições que o MHD fornece à instrumentalidade do/a assistente social.

É importante atentar para o fato de que o conhecimento científico, como força instrumental do desenvolvimento da sociedade, constitui-se objeto de disputa de interesses. O interesse social das classes é radicado nas determinações e relações fundantes da vida social, formatada pelas relações de produção e reprodução social. Estas últimas e os conflitos entre elas medeiam a direção social da produção e do complexo aparato social de reprodução, onde se localizam a arte, a política, a ideologia, a ciência, dentre outros. É bem verdade que há problemas muito sérios de ordem não apenas teórico-política, mas também ideológica no campo da produção do conhecimento. Desvendá-los supõe transpor as armadilhas dos modismos acadêmicos, compreendêlos exige o exercício de recusa absoluta das aparências imediatas dos fenômenos e, ao mesmo tempo, realizar a árdua tarefa do conhecimento da realidade (SANTOS, 2018).

Na grade curricular do/a estudante de Serviço Social podemos eleger, de forma geral, algumas disciplinas relacionadas especificamente à pesquisa, como Pesquisa Social - que deve corresponder à pesquisa em serviço social, presente nas diretrizes, assim como as orientações e/ou disciplinas de monografia, que são orientadas para o processo de produção científica. Ademais, outras disciplinas trabalham a questão da pesquisa/investigação, como o estágio obrigatório, a própria instrumentalidade e a disciplina de teoria sociológica ou metodologias aplicadas às Ciencias Sociais. Além disso, o/a estudante tem a possibilidade de integrar grupos de estudos e de pesquisa participando do Programa de Iniciação Científica (PIBIC) e outras modalidades de pesquisa, nas faculdades públicas e particulares.

Evidentemente, a totalidade dos discentes cursa uma (ou mais de uma) disciplina de pesquisa social, estágio obrigatório e produz uma monografia ou trabalho de cunho técnico-científico como requisito de conclusão de curso, ao final da graduação, mas nem todos os estudantes conseguem avançar, em profundidade, na operacionalidade da pesquisa. Já os estudantes que, em geral, participam de grupos de pesquisas, ao longo da formação, adquirem maior habilidade à produção de conhecimento e produzem, consequentemente, alguma pesquisa de caráter científico, o que potencializa a perspectiva da formação continuada e da qualificação profissional, assim como o fortalecimento dos cursos de pós-graduação e a consolidação da pesquisa na área do serviço social.

Entretanto, a maioria dos grupos de pesquisa encontra-se nas universidades públicas e, no Brasil, dos 453 cursos, $83,2 \%$ (362) encontra-se em faculdades privadas, de acordo com o Censo de Educação Superior (BRASIL, 2012). Os/as discentes de serviço social possuem o perfil trabalhador conciliando estudos e trabalho, o que faz com que tenham pouca ou nenhuma possibilidade de praticar a extensão e a pesquisa, para além do ensino formal. Além disso, em $2009,54,7 \%$ das vagas ofertadas para o curso de serviço social era na modalidade $\mathrm{EaD}$, fazendo com que, atualmente, a maior parte da formação seja privada e a distância, o que não apenas impossibilida o tripé ensino-pesquisa-extensão, como fragiliza os aspectos mais importantes e fundamentais do próprio ensino, construído com a vivência universitária, com a participação coletiva da dinâmica da sala de aula inerente à formação político-pedagógica entre discentes e docentes.

Diante disso, é imprescindível, a nosso juízo, uma defesa intransigente das pesquisas e dos grupos de pesquisas nas unidades de formação acadêmica. São nestas que a pesquisa se mantém viva e faz parte da engranagem formativa dos/as discentes. Por isso, é necessário hoje, mais do que nunca, diante de ameaças tão evidentes que impactam a nossa perspectiva teórica-metodológica e o nosso projeto-ético político hegemônicos, que defendamos as orientações dadas pelas Diretrizes Curriculares nas Instituições de Ensino Superior (IES), 
pois a sua implementação é garantia de que os/as assistentes sociais possam acessar o mercado de trabalho com fundamentação teórico-metodológica, assegurando "um agir-refletir crítico e uma intervenção que possa contribuir para a transformação social, cuja responsabilidade é de toda a sociedade e não somente do Serviço Social". (SETUBAL, 2017, p. 67).

Ao garantir o que as Diretrizes Curriculares preconizam na formação profíssional, estaremos formando assistentes sociais habilitados a compreender as contradições da sociedade capitalista, das políticas sociais nessa totalidade e as raízes das expressões das questões sociais. O/A assistente social que possuiu uma formação crítica e sólida pode responder de inúmeras formas às demandas sociais, no cotidiano profíssional, tendo compreensão dos limites e das próprias contradições de sua ação, apropriando-se da instrumentalidade e da mediação enquanto categorias imprescindíveis da práxis profissional. Portanto, teoria/investigação e prática/intervenção compõem uma unidade dialética consubstanciada em processos que requisitam da formação e da atuação profissional crítica e comprometimento com a realização de pesquisas com direção e engajamento social.

\section{O Método: uma problemática crucial da pesquisa}

É inegavel que passamos, atualmente, por um acirramento da disputa de direção intelectual e moral da profissão, e essa disputa ganha muita força no âmbito da formação profissional. As concepções que pleiteiam a hegemonia no interior do serviço social pautam um debate que questiona a perspectiva de formação que se fundamenta na autonomia da universidade, no seu viés crítico e plural, ou na tecnicidade do mercado liberal (PEREIRA, 2005). Não à toa assistimos ao crescimento político e teórico de contracorrentes não hegemônicas no serviço social, como o "Serviço Social libertário" e as suas 23 teses pela reforma do Serviço Social ${ }^{3}$, que promulgam a abertura do curso ao mercado liberal e seu aprofundamento tecnicista. Isso vem impactando não apenas a orientação teórica e política da formação profissional, mas também o exercício profissional em diversos vetores. Casos como esse são sintomáticos do predomínio das análises superfíciais, aligeiradas e fragmentadas da sociedade; da exacerbação do individualismo, em detrimento da totalidade e do caráter coletivo das relações sociais; do aumento das privatizações e das omissões estatais e, evidentemente, da precarização das condições objetivas da classe trabalhadora - que é constitutiva da vida de discentes e docentes dos cursos de Serviço Social espalhados pelo Brasil. Crescem, nesse sentido, as correntes antiteóricas - como a atual "pós-verdade" que nega a própria evolução científica e a constatação empírica dos fenômenos sociais.

Mas, isso não é na sua origem um fenômeno absolutamente novo. Desde meados do século passado, as teorias pós-modernas que buscaram atestar a crise das meta-narrativas modernas, (liberalismo/marxismo) disseminaram uma interpretação ideológica da vida social que obscurece e retira a centralidade das contradições sociais presentes nas condições de produção e nas relações sociais de (re)produção capitalistas. A cultura pós-moderna propõe um sistema de análises teórico-sociais que restringe a interpretação do conjunto da vida social, a partir da relativização dos fenômenos e superdimensionamento de experiências focais e subjetivistas. Buscou, com isso, elidir a estrutura teórico-política e categorial da tradição do pensamento crítico moderno e criar uma cultura de pulverização "ideal" do real como totalidade histórica. Os sistemas explicativos de tal interpretação teórica tentam dar conta de "olhar" e compreender a realidade de forma fragmentada e descolada das suas determinações, objetivações e contradições fundantes. Semântica e teoricamente tais análises buscaram empregar obsolescência analítica a categorias tais como: trabalho, lutas de classes, revolução, exploração, alienação, dentre outras categorias ontológicas e reflexivas dispostas pela tradição marxista (SANTOS, 2018).

Como é sabido a direção hegemônica do Serviço Social possui adesão crítica e marxista. Consequentemente, supõe-se um esforço coletivo dos vetores profissionais para garantir e estimular uma compreensão analítica de realidade auxiliada pelo conhecimento produzido pelas pesquisas científicas. $\mathrm{Na}$ orientação majoritária preconizada pelo conjunto da legislação político-normativa que regulamenta a formação e o exercício profissional, a perspectiva crítica é uma conquista coletiva que se consolidou como patrimônio do serviço social brasileiro, da qual faz parte o arcabouço teórico-metodológico de análises materialistas históricas e dialéticas da sociedade, em especial, das expressões sociais do que se convencionou chamar de "questão social", fenômeno inerente à consolidação e madurez do capitalismo imperialista.

Portanto, a pesquisa, as metodologias e o método, possibilitam-nos o desvendamento do real, articulando a totalidade, a particularidade e a singularidade, enquanto categorias esquemáticas de compreensão. Entretanto, a maior parte das pesquisas atualmente, sobretudo nas Ciências Sociais, nega a possibilidade investigativa e transformadora do marxismo. Não raro, encontramos análises superficiais e fragmentadas da realidade, que proclamam um infindável subjetivismo e negam qualquer possibilidade de objetividade dos fenômenos, assim negando a própria materialidade da vida social. 
Muitas das pesquisas realizadas tanto na graduação, quanto na pós-graduação em Serviço Social, não apenas incorrem num contínuo ecletismo, como nem sequer apresentam o método utilizado. Na pesquisa de Luciana Cantalice (2019), que analisou 401 artigos, 647 dissertações, 82 teses e mais de 10.000 artigos do Congresso Brasileiro de Serviço Social (CBAS) e do Encontro Nacional de Pesquisadores/as em Serviço Social (ENPESS), foi possível constatar que mais de $79 \%$ dos artigos não apresentaram o método de análise que guiou o texto, $19 \%$ apresentam o MHD como método de análise e quase $2 \%$ apresentam o positivismo. No caso das dissertações e teses, quase $30 \%$ não problematizam o método de análise de suas pesquisas. Esses dados, mostrados no universo da pesquisa da autora, indicam-nos uma tendência de fragilidade e descuido nas análises teóricas no Serviço Social, em relação ao MHD, assim como, o predomínio do eclestismo teórico e metodológico no rol dessas pesquisas.

Para Setubal (2017, p. 65) "a coexistência de correntes teóricas de interesses e métodos tão diferentes tem dificultado o rompimento com a conduta norteada pela pseudoconcreticidade ${ }^{4} \mathrm{e}$ o desvencilhamento da compreensão que se tem da práxis como sinônimo de trabalho". De alguma forma, essa reflexão nos faz pensar no sincretismo teórico ainda vigente no interior da profissão. Esse fato não carece tratamento moral de qualquer ordem, mas supõe o exercício político do desvelamento de seu significado histórico e teórico na trajatória da profissão, e isso deve ser feito e demonstrado no âmbito da batalha das ideias. Não se trata de uma abstração do fato de que perspectivas teóricas diversas influenciam vetores profissionais na formação e na atuação profíssional, pelo contrário, trata-se da compreensão de que a existênica de um projeto profíssional coerente, supõe a vinculação a uma perspectiva teórica específica. No fundo, estamos nos referindo à necessidade de defesa do projeto profíssional hegemônico no serviço social, e isso perpassa pela disputa permanente da sua direção intelectual, isto é, teórico-política.

A compreensão dessa tarefa deve nos manter vigilantes e intransigentes quanto à qualidade teórica e à direção social das nossas pesquisas, em todos os níveis de formação na área do serviço social. No ensino de graduação essa realidade é dramática, porque parte considerável dos/as estudantes acaba não compreendendo com profundidade o MHD e a maneira de como utilizá-lo, enquanto meio de análise dos fenômenos sociais. Não raramente é possível encontrar monografias de graduação que em seus aspectos teóricos e metodológicos apresentam o MHD como o método de análise, mas quando a análise é feita, os/as alunos/as tendem a superficializar o método, fundamentando-se em diversas perspectivas teóricas (inclusive inconciliáveis, como a fenomenologia que tem como pressuposto a imparcialidade e negação da apreensão da essência dos fenômenos sociais), como se todas fossem compatíveis, sem realizar as devidas mediações. Percebe-se, então, que existe um "jargão" nas produções do serviço social, no qual os discentes se veem, em certa medida, obrigados/as a mencionar o MHD como método de análise, mas não efetivam a análise por meio dessa orientação, ou, nem sequer apresentam algum método de análise, como já demonstrado anteriormente, na pesquisa de Catalice (2019).

É necessário identificar o que vem causando essa incompreensão e superficialidade do MHD. Algumas hipóteses podem ser consideradas, a exemplo de que os/as discentes possuem pouco tempo para a realização de uma pesquisa que combina aprofundamento teórico e imersão prática e empírica por meio da coleta de dados, que não necessariamente coincide com o campo de estágio. Muitos alunos/as optam por pesquisar fenômenos sociais outros, que não tem relação alguma com o estágio. Evidentemente, trata-se da liberdade dos/as mesmos/as em escolher o que pesquisar, entretanto, muitos/as alunos/as que tem o primeiro contato mais direto com a pesquisa apenas na construção da monografia tendem a ter inúmeras dificuldades da efetivação da pesquisa proposta. Por isso, as Diretrizes Curriculares enfatizam que preferencialmente o Trabalho de Conclusão de Curso (TCC) deve ser relacionada a prática do estágio no decorrer do curso. Assim, o TCC

\footnotetext{
é uma exigência curricular para obtenção de diploma no curso de graduação em serviço Social. Deve ser entendido como um momento de síntese e expressão da totalidade da formação profissional. É o trabalho no qual o aluno sistematiza o conhecimento resultante de um processo investigativo, originário de uma indagação teórica, preferencialmente gerada a partir da prática do estágio no decorrer do curso. Este processo de sistematização, quando resultar de experiência de estágio, deve apresentar os elementos do trabalho profissional em seus aspectos teórico-metodológico-operativos. Realiza-se dentro de padrões e exigências metodológicas e acadêmico-científicas. Portanto, o TCC se constitui numa monografia científica elaborada sob a orientação de um professor e avaliada por banca examinadora. (ASSOCIAÇÃO BRASILEIRADE ENSINO E PESQUISA EM SERVIÇO SOCIAL, 1996, p. 19, grifo do autor).
}

Compreendemos que as Diretrizes recomendam que, preferencialmente, o/a aluno/a realize a sua investigação e o seu TCC a partir de indagações originárias da prática do estágio, porque por meio do estágio, que contabiliza 2.700 horas na grade curricular, o/a aluno consegue aprofundar a análise da prática profíssional e das expressões da questão social, contando supervisão sistemática, acadêmica e profíssional, garantindo maior 
rigor teórico-metodológico. Portanto, parece-nos mais acertado que quando o/a discente não tem possibilidade de aprofundar a pesquisa por meio de outras disciplinas, nem pela participação em grupos de pesquisa, efetivando o PIBIC, por exemplo, e nem pela imersão em outros espaços formativos, como movimentos sociais e a própria extensão, este/a deveria realizar o seu TCC relacionado à experiência do campo de estágio. Essa orientação aparece como uma defesa daquilo que já é preconizado pelas Diretrizes, além disso, tem o objetivo de postular a qualidade da pesquisa do tipo inteligente, isto é, que se expressa como acúmulo referente ao processo contínuo da formação.

\section{Considerações finais}

A despeito das Diretrizes darem direção ao currículo de formação de graduação, estabelecendo os conteúdos destinados à pesquisa e à obrigatoriedade do TCC e do estágio, há fatores reais que obstaculizam as possibilidade de concretização do currículo, na atualidade. A conjuntura desse período recente, marcado pelo contexto de elaboração e implementação das Diretrizes nas unidades de formação acadêmica (UFAs), traz no seu compósito histórico e social grandes impecílios à formação de qualidade.

Os interesses da acumulação capitalista conflituam e se consubstanciam no interior das instituições como condição impeditiva da crítica social ao status quo. As mediações que se elidem em defesa desse propósito ganham no seio das instituições uma forma ideológica complacente com os desígnos do capital, garantindo sem grandes dificuldades a constituição de uma espécie de pensamento único, isto é, o pensamento das ideias dominantes, porque é em si mesmo, funcional aos interesses das classses que dominam.

Numa sociedade de classes, as classes dominantes buscam compreender a realidade e orientar a intervenção nela de modo a favorecer os seus interesses que, não esqueçamos, são sempre apresentados como interesses universais. Não se trata de querer ou não. Trata-se de uma necessidade inescapável e nenhuma instância da vida social se aparta dessa determinação, porque o poder das ideias dominantes está vinculado à força material que as dão sustentação, na sociedade que vivemos. E isso tem uma existência prática altamente alienada e alienante.

A penetração dessa dinâmica no universo acadêmico, da pesquisa e de profíssões como o serviço social é inexorável. Contudo, as determinações não podem ser pensadas como realidades imutáveis, porque a existência é tensionada por movimentos de resignação, mas também de resistência possibilitada pelas contradições próprias da totalidade social.

Vale a ressalva de que a totalidade não significa a inteireza dos fatos da realidade total, mas, sim, a análise da "realidade como um todo estruturado, dialético, no qual ou do qual um fator qualquer (classes de fatos, conjunto de fatos) pode vir a ser racionalmente compreendido" (KOSIK, 2010, p. 44). Essa perspectiva da totalidade é um postulado aqui referido e inarredável da perspectiva teórica reivindicada pelo projeto político profissional do serviço social brasileiro, cuja compreensão e defesa da pesquisa social tem no materialismo histórico dialético, a chave de compreensão do mundo e uma ferramenta teórica, por excelência, de reinvenção da práxis social.

Do ponto de vista da formação profissional, essa resistência supõe a criatividade coletiva e o empenho de vetores profissionais à frente da formação na pesquisa e na atuação profissional, envolvendo inclusive o conjunto das entidades representativas da profissão. O serviço social precisa voltar a colocarse na agenda das suas próprias pesquisas, isto é, ser objeto das investigações realizadas pela comunidade de pesquisadores da área. Uma nova pesquisa sobre a implementação das Diretrizes Curriculares, por exemplo, poderia abrir possibilidades de um debate nacional importante, capaz de nos demonstrar não apenas as nossas debilidades teóricas metodológicas ou as tendências de falência do nosso projeto de formação, mas fomentar a criatividade, o empenho e a capacidades de um enfrentamento coletivo dos nossos maiores desafios. Afinal, é preciso conhecê-los, desvendá-los, porque quem erra na análise também equivoca-se na ação.

\section{Referências}

ASSOCIAÇÃO BRASILEIRADE ENSINO E PESQUISAEM SERVIÇO SOCIAL (ABEPSS). Diretrizes gerais para o curso de Serviço Social (Com base no Currículo Mínimo aprovado em Assembléia Geral Extraordinária de 8 de novembro de 1996). Rio de Janeiro, nov. 1996. Disponível em: http://www.abepss.org.br/arquivos/textos/documento 201603311138166377210.pdf. Acesso em: 30 jun. 2019. ASSOCIAÇÃO BRASILEIRADE ENSINO E PESQUISAEM SERVIÇO SOCIAL(ABEPSS). Quem Somos. 2019. Disponível em: http://www.abepss.org.br/quem-somos-1. Acesso em: 30 jun. 2019. 
BRASIL. Lei n. 8.662, de 7 de junho de 1993. Regulamenta a profissão de assistente social. Brasilia, 7 de junho de 1993. Disponível em: http://www.planalto.gov.br/ccivil_03/leis/18662.htm. Acesso em: 15 jun. 2019.

BRASIL. Lei n. 9.394, 20 de dezembro de 1996. Lei de Diretrizes e Bases da Educação Nacional. Brasília, 20 de dezembro de 1996. Disponível em: http://www.planalto.gov.br/ccivil_03/leis/19394.htm. Acesso em: 15 jun. 2019.

BRASIL. Ministério da Educação e Cultura. Censo de Educação Superior, 2012. Disponível em: http://download.inep.gov.br/ download/superior/censo/2012/resumo_tecnico_censo_educacao_superior_2012.pdf. Acesso em: 30 jun. 2019.

BRASIL. Resolução CNE/CES 6, de 23 de setembro de 1982. Fixa os mínimos de conteúdo e de duração do Curso de Serviço Social, com base no Parecer n. 412/82, homologado pela Ministra da Educação. Brasília, 1982.

BARROCO, Maria Lucia Silva; TERRA, Sylvia Helena. Código de ética do (a) assistente social comentado. São Paulo: Cortez, 2014.

CANTALICE, Luciana, B. O. As atuais tendências teórico-metodológicas da produção de conhecimento do Serviço Social. Pesquisa de Pós-doutorado. Programa de Pós-graduação em Serviço Social da Universidade Federal do Rio Grande do Norte, 2019.

COUTINHO, C. N. O estruturalismo e a miséria da razão. Rio de Janeiro: Paz e Terra, 1972.

GUERRA, Yolanda. A dimensão investigativa no exercício profissional. Serviço Social: direitos sociais e competências profissionais. Brasilia: CFESS/ABEPSS, 2009. p. 701-718.

KOSIK, Karel. Dialética do concreto. Tradução: Célia Neves; Alderico Toríbio. Rio de Janeiro: Paz e Terra, 2010.

PAULO NETTO, José. Ditadura e Serviço Social: uma análise do Serviço Social no Brasil pós-64. São Paulo: Cortez, 2017.

PAULO NETTO, José. Introdução ao método da teoria social. In: Conselho federal de Serviço Social; Associação Brasileira de Ensino e Pesquisa em Serviço Social. Serviço Social: direitos sociais e competências profissionais. Brasília: CFESS/ ABEPSS, 2009. p. 769-806.

PEREIRA, Potyara A. P. A utilidade da pesquisa para o Serviço Social. Serviço Social e Saúde, v. 4, n. 1, p. 17-28, 2005.

SANTOS, Claudia Mônica dos. Na prática a teoria e outra?: mitos e dilemas na relacao entre teoria, pratica instrumentos e tecnicas no Servico Social. Lumen Juris, 2011.

SANTOS, Tássia Monte. Lutas de classes e perspectiva revolucionária na tradição Marxista: notas introdutórias. In: Marxismo, Política Social e Direitos. São Paulo: Cortez, 2018.

SETUBAL, Aglair Alencar. Desafios à pesquisa no Serviço Social: da formação acadêmica à prática profissional. Katálysis, v. 10, n. esp., p. 64-72, 2007.

SOUZA, Jamerson Murillo Anunciação de. Três notas sobre o sincretismo no Serviço Social. Serviço Social \& Sociedade 119: Direitos humanos em questão, p. 531, 2014.

\section{Notas}

1 Em 1946, aAssociação Brasileira de Escolas de Serviço Social (ABESS) foi criada, passando a se chamar Associação Brasileira de Ensino de Serviço Social, em 1979. Em 1996, a ABESS sofre a sua última alteração tomando-se a Associação Brasileira de Ensino e Pesquisa em Serviço Social (ABEPSS), ao incorporar o Centro de Documentação e Pesquisa em Políticas Sociais (CEDEPSS). Sendo que "os objetivos dessa fusão foram: fortalecer a indissociabilidade entre ensino, pesquisa e extensão na formação profissional; articular graduação e pós graduação; fortalecer a natureza científica da entidade; dar maior organicidade a pesquisa, o que culminou com a criação dos Grupos Temáticos de Pesquisa (GTPs) em 2010."(ABEPSS, 2019).

2 De acordo com a Lei, em seu Art. $4^{\circ}$ Constituem competências do Assistente Social:

"VII - planejar, executar e avaliar pesquisas que possam contribuir para a análise da realidade social e para subsidiar ações profissionais;

Art. $5^{\circ}$ Constituem atribuições privativas do Assistente Social:

I - coordenar, elaborar, executar, supervisionar e avaliar estudos, pesquisas, planos, programas e projetos na área de Serviço Social;

VIII - dirigir e coordenar associações, núcleos, centros de estudo e de pesquisa em Serviço Social'. (BRASIL,1993, grifos do autor).

3 O "Serviço Social Libertário" é um movimento iniciado por alunos/as e profissionais de Serviço Social, em 2016, por meio de redes sociais, sobretudo pelo Facebook, onde é alimentada uma página em defesa de valores liberais e individuais à profissão.

4 Para Kosik (2010, p. 15), "O complexo dos fenômenos que povoam o ambiente cotidiano e a atmosfera comum da vida humana, que, com a sua regularidade, imediatismo e evidência, penetramna consciência dos indivíduos agentes, assumindo um aspecto independente e natural, constitui o mundo da pseudoconcreticidade".

\section{Rayane Noronha Oliveira}

rayane.noronha.oli@gmail.com

Mestra em Sociologia, Universidade de Brasília (UnB)

Doutoranda em Serviço Social, Universidade Federal do Rio Grande do Norte (UFRN) 


\section{Tássia Monte Santos}

tassiamontesantos@gmail.com

Mestra em Serviço Social, Universidade Federal do Rio Grande do Norte

Doutoranda em Serviço Social, Universidade Federal de Pernambuco (UFPE)

Docente do curso de Serviço Social, Universidade Federal do Rio Grande do Norte

\section{UFRN}

Campus, Túnel da UFRN - Lagoa Nova

Natal - Rio Grande do Norte - Brasil

CEP: $59064-741$

\section{Agradecimentos}

Ao Conselho Nacional de Desenvolvimento Científico e Tecnológico (CNPq).

\section{Agência financiadora}

Não se aplica.

\section{Contribuições das autoras}

As autoras dialogaram sobre a temática, a partir do acúmulo teórico-metodológico construído na experiência em sala de aula, enquanto docentes de disciplinas referentes à pesquisa social. Partiram de debates sobre a transversalidade da pesquisa social no currículo da área e formularam algumas problematizações acerca dos desafios do tema na formação. A partir disso, as autoras, Rayane Noronha Oliveira e Tássia Monte Santos, formaram uma parceria intelectual na produção e revisão do presente texto.

Aprovação por Comitê de Ética e consentimento para participação

Não se aplica.

Consentimento para publicação

Não se aplica.

Conflito de interesses

Não há conflito de interesses. 